\title{
Chrome Complexes in Rewetting and Neutralizing Effluents and Hints for Recycling Post-Tanning Wet-Process Effluent
}

\author{
Jiacheng Wu, Yanping Gao, Jinwei Zhang, Yao Wang, Wuyong Chen* \\ National Engineering Laboratory for Clean Technology of Leather Manufacture and the Key Laboratory \\ of Leather Chemistry and Engineering of Ministry of Education, Sichuan University, \\ Chengdu 610065, China
}

Received: 28 June 2017

Accepted: 15 September 2017

\begin{abstract}
Although the treatment for recycling chrome in tanning effluents is relatively mature, the post-tanning processes have no corresponding effective technology due to the lack of knowledge about the effluents. In this work we investigated the composition and properties of rewetting and neutralizing effluents in posttanning processes. Goat skins were tanned with sulfate chrome liquor of alkalinity $33 \%$ (SC), and then conventional technologies were applied to get rewetting and neutralizing effluents (RE, NE). The effluents were separated and analyzed by ion exchange chromatography, gel filtration chromatography, ultravioletvisible absorption spectroscopy, and Fourier-transform infrared spectroscopy. Hide powder tanned by the chrome recovered from the effluents was evaluated by thermogravimetric analysis and differential scanning calorimetry. The results indicated that RE and NE showed different valent chrome complexes from SC. Released chrome mainly combined with $\mathrm{SO}_{4}{ }^{2-}$ and $\mathrm{HCOO}^{-}$through a single-point coordinate mode. Molecular weight of chrome complexes in the effluents was smaller and the tanning ability was poorer. Based on the results, the composition and properties of chrome complexes in RE and NE were understood, and some of their structures were speculated. Since these characteristics have a relationship with tanning performance, they may provide theoretical support for developing effluent-related recycling technology in the leather industry.
\end{abstract}

Keywords: chrome, neutralizing effluents, rewetting effluents, recycling technology, tanning

\section{Introduction}

With an excellent overall performance of chrome tanned leather, the chrome tanning method is always a dominant technology in leather making. While chrome in

*e-mail: wuyong.chen@163.com the tanning process helps retain the strength and quality of leather, it leads to a high amount of toxic chromate ions discharged into environmental receptors after tanning [1]. The uncontrolled release of chrome in tannery effluent increases environmental pollution concerns and health risks [2]. Therefore, whatever method is used to lower the amount of chrome salts in the final discharge, it will portend chrome as a potentially toxic source to the environment [3-4]. The chrome released into the water 
can be transported among the various environmental media through varieties of intermedia transport processes, where chrome can be taken up by human and other ecological receptors [5-6]. Therefore, elimination or minimization of the chrome in tannery effluent to reduce environmental pollution and health risks is an urgent problem in the leather industry. Reusing effluent is an efficient method for solving the problem, and knowledge of the source, composition, structures, and properties of chrome in the effluent is a prerequisite for developing related recycling technology.

The sources of the chrome in tannery effluents include two parts: the tanning and post-tanning wet processes. For tanning effluents, due to its high chrome content, tanneries have paid much more attention to its recycling. Meanwhile, a lot of processes have formed to improve the existing chrome tanning method and enhance the utilization of chrome. So far, many researchers have recycled chrome from the effluents by using the methods of direct recycling [7-8], electrolysis [9], extraction [10], and electrocoagulation [11-12]. Therefore, the problem of relative recycling technology about the tanning effluents has been solved. For the post-tanning wet process, a large number of chrome complexes will be released from collagen and enter the effluent from rewetting, neutralizing, retanning, dyeing and fat liquoring processes [13-14]. Thus $\mathrm{Cr}_{2} \mathrm{O}_{3}$ in the effluent has already reached $10-450 \mathrm{mg} / \mathrm{L}$ [15-16], and their direct emissions will cause serious environmental pollution. Therefore, to solve the problem of chrome pollution in leathermaking, more attention should not only be paid to the tanning effluents but also the post-tanning wet process. Especially the rewetting and neutralizing effluents should be played more owing to research in these two processes. Although some studies [17-18] had shown that it can serve to reduce the release of chrome complexes by adjusting the posttanning wet process, these methods just stayed in the technical regulation stage and cannot solve the problem of chrome complexes release because the composition, properties, and structures of chrome complexes in these processes are not clear.

In this work the goat skins were tanned with sulfate chrome liquor of alkalinity 33\%, and then general rewetting and neutralizing processes were applied to get the rewetting and neutralizing effluents. Ion exchange chromatography and gel filtration chromatography were used to separate the rewetting and neutralizing effluents. Ultraviolet-visible absorption spectroscopy and Fouriertransform infrared spectroscopy were combined to analyze the structure of chrome complexes. The hide powder was tanned with the chrome recovered from rewetting and neutralizing effluents, and then evaluated by thermogravimetric analysis and differential scanning calorimetry on thermal behaviours. Thus the composition, properties, and structures of chrome complexes in rewetting and neutralizing effluents could be understood, which may have great significance for the development of the rewetting and neutralizing effluents-related recycling technology.

\section{Materials and Methods}

\section{Materials}

The pickled goat skins were made in our laboratory according to conventional technology [19]. The hide powder was from the Tanning Chemical Lab of the Chinese Academy of Forestry Sciences in Nanjing. SP Sephadex C-25 cation exchange resins and SP Sephadex G-25 glucan gel resins were obtained from GE Healthcare. Chromium sulfate was produced in Aladdin Industrial Corporation. All the other compounds used were analytical reagents commercially purchased from Chengdu Kelon Chemical Reagent Factory, China.

\section{Methods}

\section{Preparation of Sulfate Chrome Liquor, Rewetting Effluents, and Neutralizing Effluents}

First, $0.2 \mathrm{~mol} / \mathrm{L}$ of sulfate chrome liquor was prepared. Then $0.0067 \mathrm{~mol}$ of sodium bicarbonate was added into $100 \mathrm{ml}$ of the liquor and stirred evenly. The alkalinity of the gained solution was finally determined to be $33 \%$ by the ASTM standard method D1067. $200 \mathrm{~g}$ of the pickled goat skin was cut into $1 \times 1 \mathrm{~cm}$ pieces. Then $7 \%$ salt water and $1 \%$ sodium bicarbonate were added into a conical flask with the pieces and shaken for $2 \mathrm{hr}$ in a water bath oscillator. Next, the samples were neutralized to $\mathrm{pH} 7$ with $\mathrm{NaHCO}_{3}$ and then the samples were washed with water for $24 \mathrm{hr}$ and again washed by distilled water to a low conductivity $(5 \mu \mathrm{S} / \mathrm{cm})$ for $12 \mathrm{hr}$. RE and NE were prepared by the craft as seen in Table $1 .(\mathrm{SC}=$ sulfate chrome liquor of alkalinity $33 \%, \mathrm{RE}=$ rewetting effluents, and $\mathrm{NE}=$ neutralizing effluents.)

\section{Separation of Ion Exchange Chromatography and Gel Filtration Chromatography}

$5 \mathrm{ml}$ of RE and NE were filtered by microporous membranes (pore size, $450 \mathrm{~nm}$ ), and then added into pretreatment SP Sephadex C-25 cation exchange chromatographic columns (inner diameter, $2.0 \mathrm{~cm}$; packed, $20.0 \mathrm{~cm}$ ). Elution conditions were selected as follows: flow velocity of eluent of $2.5 \mathrm{ml} / \mathrm{min}$, followed by using $\mathrm{H}_{2} \mathrm{O}, \mathrm{NaClO}_{4}(0.5 \mathrm{~mol} / \mathrm{L}), \mathrm{NaClO}_{4}(1.0 \mathrm{~mol} / \mathrm{L})$, $\mathrm{NaClO}_{4}(2.0 \mathrm{~mol} / \mathrm{L}), \mathrm{HCl}(2.0 \mathrm{~mol} / \mathrm{L})$, and $\mathrm{HCl}(3.0 \mathrm{~mol} / \mathrm{L})$ to elute. UV1900 UV-Vis spectrophotometer (Shanghai Jinghua Technology Instrument Co., LTD, China) was used to detect the absorbance at $420 \mathrm{~nm}$ in comparison to $\mathrm{SC}$.

$5 \mathrm{ml}$ of the filtered $\mathrm{RE}$ and $\mathrm{NE}$ were added into pretreatment SP Sephadex G-25 gel filtration chromatographic columns (inner diameter, $2.0 \mathrm{~cm}$, packed, $80.0 \mathrm{~cm}$ ). Elution conditions were selected as follows: flow velocity of eluent, $2.5 \mathrm{ml} / \mathrm{min} ; \mathrm{H}_{2} \mathrm{O}$ was used to elute. A UV-Vis spectrophotometer was used to detect the absorbance at $420 \mathrm{~nm}$ in comparison to SC [20-21]. 
Table 1. Craft of the tanning and post-tanning wet processes.

\begin{tabular}{|c|c|c|c|c|c|c|}
\hline Processes & Materials & Float & Temperature $\left({ }^{\circ} \mathrm{C}\right)$ & Dosage (\%) & Time (min) & Illustration \\
\hline \multirow{3}{*}{ Pickling } & $\mathrm{NaCl}$ & \multirow{3}{*}{1} & \multirow{3}{*}{22} & 7 & 5 & \multirow{3}{*}{$\mathrm{pH}=2.8$} \\
\hline & $85 \%$ formic acid & & & 0.5 & 10 & \\
\hline & sulfuric acid & & & 1 & 180 & \\
\hline \multirow{2}{*}{ Tanning } & $\mathrm{SC}$ & \multirow{2}{*}{0.8} & 22 & \multirow{2}{*}{$1.2-1.4$} & 120 & $\mathrm{pH}=2.8$ \\
\hline & Sodium bicarbonate & & 40 & & 120 & Collecting the effluents \\
\hline Standing & & & & & $24 \mathrm{hr}$ & \\
\hline \multicolumn{7}{|l|}{ Wringing } \\
\hline Rewetting & formic acid & 1.5 & $38-40$ & 0.3 & & \\
\hline Streaming & & & & & 10 & \\
\hline Neutralizing & Sodium formate & 1.5 & 35 & 2 & 90 & Collecting the effluents \\
\hline
\end{tabular}

Analysis of Fourier Transform Infrared Spectroscopy (FT-IR) and Ultraviolet-Visible Absorption Spectroscopy (UV-Vis)

After separation of IEC, the collected components were freeze-dried and dissolved with distilled water. FTIR spectra were obtained on a Magna IR506 (Nicolet Ltd, USA) FT-IR spectrophotometer using $\mathrm{KBr}$ disk in the range 4,500-500 $\mathrm{cm}^{-1}$. A UV-Vis spectrophotometer was used to detect the obtained liquor at $300-800 \mathrm{~nm}$. R values were calculated using Formula (1):

$$
\mathrm{R}=\frac{\varepsilon 1}{\varepsilon 2}
$$

...where $\varepsilon 1$ is molar absorption coefficient of chrome in $420 \mathrm{~nm}$ and $\varepsilon 2$ is molar absorption coefficient of chrome in $580 \mathrm{~nm}$.

\section{Analysis of Thermal Properties}

$1 \mathrm{~g} / 100 \mathrm{ml}$ chrome solution was prepared by the chrome recovered from RE and NE. Then $1 \mathrm{~g}$ hide powder was tanned by $100 \mathrm{ml}$ of the solution for $2 \mathrm{hr}$. Next, formic acid or sodium bicarbonate was used to adjust the $\mathrm{pH}$ to 4.0 , respectively. After that, the powder was dried completely for $12 \mathrm{hr}$ at $30^{\circ} \mathrm{C}$. Finally, the samples were put in a dryer with saturated sodium sulphite and kept at $25^{\circ} \mathrm{C}$ with relative air humidity of $65 \%$ [22]. Thermogravimetric (TG) analysis of the samples were measured on a TG209 (NETZSCH Ltd., Germany) thermogravimetric apparatus in the stream of nitrogen as follows: mass of the sample $3-5 \mathrm{mg}, 40-400^{\circ} \mathrm{C}$, and heating rate $10^{\circ} \mathrm{C} \cdot \mathrm{min}^{-1}$. Differential scanning calorimetry (DSC) of the samples was determined on a PC-200 (NETZSCH Ltd., Germany) differential scanning calorimeter in the stream of nitrogen as follows: mass of the sample $3-5 \mathrm{mg}, 25-250^{\circ} \mathrm{C}$, and heating rate $10^{\circ} \mathrm{C} \cdot \mathrm{min}^{-1}$.

\section{Results and Discussion}

\section{Charge Characteristics of} the Chrome Complexes

The IEC of SC, RE, and NE are shown in Fig. 1. Takenouchi [23] confirmed that chromatographic peaks I-VI represent anionic-zerovalent, monovalent, bivalent, trivalent, tetravalent, and pentavalent chrome complexes, respectively. Notably, RE consists of anionic-zerovalent, monovalent, bivalent, trivalent, and tetravalent chrome complexes (as seen in Fig. 1b). NE are just composed of anionic-zerovalent and monovalent chrome complexes (Fig. 1c). SC are separated into five components (anioniczerovalent, monovalent, bivalent, trivalent, and tetravalent chrome complexes; Fig. 1a). The composition of chrome complexes in SC, RE, and NE can be calculated based on the area of ion-exchange chromatographic peak (Table 2). $(\mathrm{CRE}=$ chrome in $\mathrm{RE}$; $\mathrm{CNE}=$ chrome in $\mathrm{NE}$; and $\mathrm{CSC}=$ chrome in SC.)

Charge distribution of CSC is more uniform, but the contents of CRE and CNE are different (as seen in

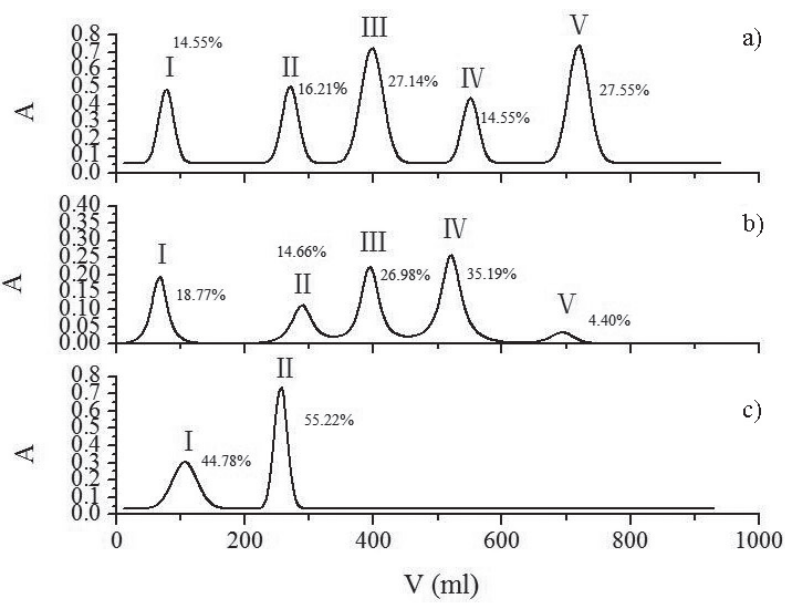

Fig. 1. IEC of SC a), RE b), and NE c). 
Table 2. Composition of chrome complexes.

\begin{tabular}{|c|c|c|c|c|c|}
\hline $\begin{array}{c}\text { Chromatographic } \\
\text { peak }\end{array}$ & I & II & III & IV & V \\
\hline Valence state & $\begin{array}{c}\text { anionic- } \\
\text { zerovalent }\end{array}$ & +1 & +2 & +3 & +4 \\
\hline CRE (\%) & 18.77 & 14.66 & 26.98 & 35.19 & 4.40 \\
\hline CNE(\%) & 44.78 & 55.22 & 0 & 0 & 0 \\
\hline CSC (\%) & 14.55 & 16.21 & 27.14 & 14.55 & 27.55 \\
\hline
\end{tabular}

Table 2). The contents of anionic-zerovalent, $+1,+2$, +3 , and +4 valent chrome complexes are, respectively, $18.77 \%, 14.66 \%, 26.98 \%, 35.19 \%$, and $4.40 \%$ in CRE. The corresponding components of CNE are $44.78 \%$, $55.22 \%, 0 \%, 0 \%$, and $0 \%$, respectively. Therefore, the main components of $\mathrm{CRE}$ are +2 and +3 valent chrome complexes. However, in CNE there are only anioniczerovalent and +1 valent chrome complexes. The results indicate that low-positive electricity chrome complexes are easy to be eluted in CRE and CNE because the binding capacity between anionic-zerovalent low positive electricity chrome complexes and collagen is weak for forming instable chrome complexes. In the process of neutralization $\mathrm{pH}$ is increased obviously and the chrome complexes are difficult to be released in high $\mathrm{pH}$ owing to the strong combination between the chrome complexes and collagen, and thus the charge of chrome complexes increases with the $\mathrm{pH}$ in this process. Because the neutralizing process occurred after the rewetting process, quite a part of the chrome had been already released. Therefore, a few of the chrome complex components were eluted from the neutralizing process. Thus, compared with CRE the components of $+2,+3$, and +4 valent chrome complexes were missing in $\mathrm{CNE}$.

\section{Molecular Weight of the Chrome Complexes}

As for research on the structure of coordination compounds, GFC is often used to analyze molecular weight distribution. And it said that the retention time of the large molecular weight about the complexes is shorter, but on the contrary it is longer with small molecular weight during the gel filtration chromatography separation process. The results of GFC of SC, RE, and NE are shown in Fig. 2. Peak II is the main part of CRE (peak I 14\% and peak II $86 \%$ ). The chrome complexes in peak II began to flow from the chromatographic column at $196 \mathrm{~min}$ and they were eluted completely at $284 \mathrm{~min}$ (Fig. 2b). At 270 min, CNE got going to flow from the chromatographic column while they were eluted totally at $360 \mathrm{~min}$ (Fig. 2c). Apparently, when the elution arrived at $172 \mathrm{~min}$, CSC was gradually eluted from the column and finished at $280 \mathrm{~min}$ (Fig. 2a). Although there was a minor difference among the tested samples, the main molecular weight of CRE and CNE was smaller than that of CSC. As a consequence, this may provide enlightenment for the development of RE- and NE-related recycling technologies.

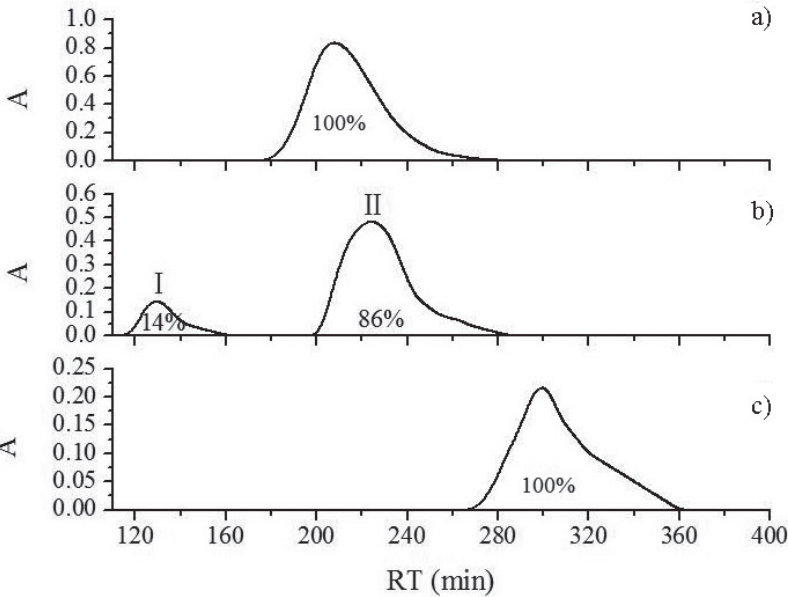

Fig. 2. GFC of SC (a), RE (b), and NE (c),

\section{UV-Vis}

The $\mathrm{R}$ value of $\left[\mathrm{Cr}\left(\mathrm{H}_{2} \mathrm{O}\right)_{6}\right]^{3+}$ is 1.19 . When $\mathrm{R}$ value is less than $1.19, \mathrm{Cr}^{3+}$ and ligands are combined with each other through a single-point coordination mode, and the ligand is used as a bridge bond to make two or more $\mathrm{Cr}^{3+}$ combine with each other to form multinuclear complexes as $\mathrm{R}$ value is more than 1.19 . So, high $\mathrm{R}$ value results in many more bridging bonds between the central ion and ligands, and greater volume of the complex [23]. R values of chrome complex constituents I-V in CSC are 1.08, 1.10, $1.09,1.15$, and 1.36 , respectively, while they are $2.33,0.86$, $0.85,0.87$, and 0.80 in CRE (Table 3 ). However, $\mathrm{R}$ values of chrome complex constituents I and II in CNE are 0.91 and 0.85. Obviously, most of the $\mathrm{R}$ values in CRE and CNE are less than 1.19, though the $\mathrm{R}$ value of constituent $\mathrm{I}$ in CRE is 2.33 - quite a bit greater than 1.19 (the proportion is only $18.77 \%$ ). Therefore, $\mathrm{Cr}^{3+}$ is combined with ligands mainly through a single-point coordination mode so that there fewer bridge linkages between $\mathrm{Cr}^{3+}$ and ligands, and the volume was small.

\section{FT-IR Spectra}

FT-IR absorption peaks and coordination modes of CRE and CNE are shown in Table 4. For constituent I there are four absorption bands in the range of $900-1,300 \mathrm{~cm}^{-1}$, thus the center ion $\mathrm{Cr}^{3+}$ is mainly combined with $\mathrm{SO}_{4}^{2-}$ through the double-point coordination mode.

Table 3. $\mathrm{R}$ values of each constituent of the chrome complexes.

\begin{tabular}{|c|c|c|c|c|c|}
\hline \multirow{2}{*}{} & \multicolumn{5}{|c|}{ R values } \\
\cline { 2 - 6 } & I & II & III & IV & V \\
\hline CSC & 1.08 & 1.10 & 1.09 & 1.15 & 1.36 \\
\hline CRE & 2.33 & 0.86 & 0.85 & 0.87 & 0.80 \\
\hline $\mathrm{CNE}$ & 0.95 & 0.80 & 0.83 & - & - \\
\hline
\end{tabular}


Table 4. FT-IR absorption peaks and coordination mode of CRE and CNE.

\begin{tabular}{|c|c|c|c|c|c|}
\hline Component & Scope $\left(\mathrm{cm}^{-1}\right)$ & Peak $\left(\mathrm{cm}^{-1}\right)$ & Number & Ligand & Coordination mode \\
\hline \multicolumn{6}{|c|}{ CRE } \\
\hline \multirow{3}{*}{ I } & $900-1300$ & $1,059,1,122,1,174,1,230$ & 4 & $\mathrm{SO}_{4}^{2-}$ & double-point \\
\hline & $\begin{array}{l}1,680-1,550 \\
1,465-1,370\end{array}$ & $\begin{array}{l}1,632 \\
1,445\end{array}$ & 2 & $\mathrm{HCOO}^{-}$ & single-point \\
\hline & 3,400 & 3,423 & 1 & $\mathrm{OH}^{-}$ & ---- \\
\hline \multirow{3}{*}{ II } & $900-1,300$ & $1,089,1,109,1,121$ & 3 & $\mathrm{SO}_{4}^{2-}$ & single-point \\
\hline & $\begin{array}{l}1,680-1,550 \\
1,465-1,370\end{array}$ & $1,619,1,638,1,402$ & 3 & $\mathrm{HCOO}^{-}$ & single-point \\
\hline & 3,400 & 3,416 & 1 & $\mathrm{OH}^{-}$ & ---- \\
\hline \multirow{3}{*}{ III } & $900-1,300$ & $1,089,1,111,1,144$ & 3 & $\mathrm{SO}_{4}^{2-}$ & single-point \\
\hline & $\begin{array}{l}1,680-1,550 \\
1,465-1,370\end{array}$ & $1,618,1,638,1,400$ & 3 & $\mathrm{HCOO}^{-}$ & single-point \\
\hline & 3,400 & 3,415 & 1 & $\mathrm{OH}^{-}$ & ---- \\
\hline \multirow{3}{*}{ IV } & $900-1,300$ & $1,089,1,111,1,143$ & 3 & $\mathrm{SO}_{4}{ }^{2-}$ & single-point \\
\hline & $\begin{array}{l}1,680-1,550 \\
1,465-1,370\end{array}$ & $1,619,1,638,1,417$ & 3 & $\mathrm{HCOO}^{-}$ & single-point \\
\hline & 3,400 & 3,416 & 1 & $\mathrm{OH}^{-}$ & ---- \\
\hline \multirow{3}{*}{$\mathrm{V}$} & $900-1,300$ & $1,088,1,110,1,141$ & 3 & $\mathrm{SO}_{4}^{2-}$ & single-point \\
\hline & $\begin{array}{l}1,680-1,550 \\
1,465-1,370\end{array}$ & $\begin{array}{l}1,631 \\
1,421\end{array}$ & 2 & $\mathrm{HCOO}^{-}$ & single-point \\
\hline & 3,400 & 3,426 & 1 & $\mathrm{OH}^{-}$ & ---- \\
\hline \multicolumn{6}{|c|}{ CNE } \\
\hline \multirow{3}{*}{ I } & $900-1,300$ & $1,007,1,070,1,171,1,230$ & 4 & $\mathrm{SO}_{4}^{2-}$ & double-point \\
\hline & $\begin{array}{l}1,680-1,550 \\
1,465-1,370 \\
\end{array}$ & $\begin{array}{l}1,636 \\
1,459 \\
\end{array}$ & 2 & $\mathrm{HCOO}^{-}$ & single-point \\
\hline & 3,400 & 3,380 & 1 & $\mathrm{OH}^{-}$ & ---- \\
\hline \multirow{3}{*}{ II } & $900-1,300$ & $941,1,080,1,143$ & 3 & $\mathrm{SO}_{4}^{2-}$ & single-point \\
\hline & $\begin{array}{l}1,680-1,550 \\
1,465-1,370\end{array}$ & $\begin{array}{l}1,622 \\
1,465\end{array}$ & 2 & $\mathrm{HCOO}^{-}$ & single-point \\
\hline & 3,400 & 3,423 & 1 & $\mathrm{OH}^{-}$ & ---- \\
\hline
\end{tabular}

Meanwhile, three absorption bands are observed in the range of $900-1,300 \mathrm{~cm}^{-1}$ due to the presence of constituents II-V of CRE and constituent II of CNE, hence $\mathrm{Cr}^{3+}$ combined with $\mathrm{SO}_{4}^{2-}$ through a single-point coordination mode [24]. As to constituents I-V of CRE and constituents I and II of CNE, there is an asymmetric stretching vibration absorption peak at 1,550-1,680 $\mathrm{cm}^{-1}$ and a symmetric stretching vibration absorption peak in the range of $1,370-1,465 \mathrm{~cm}^{-1}$. Furthermore, the peak separation between the two absorption peaks is quite small, indicating $\mathrm{Cr}^{3+}$ mainly combined with $\mathrm{HCOO}^{-}$ through a single-point coordination mode. As a consequence, the center ion $\mathrm{Cr}^{3+}$ of $\mathrm{CRE}$ and $\mathrm{CNE}$ primarily combined with the ligands through a singlepoint coordination mode.

As the chrome complex in the solution is a variable balance system, it is not possible to directly determine the true structure of them at present. But, combined with the charge distribution (seen in Table 2) and $\mathrm{R}$ value (presented in Table 3) of each chrome complex constituent, the structures of the chrome complexes in CRE and CNE may be represented as shown in Figs 3-4.

\section{Thermal Properties}

The literature shows that weightlessness rate and maximum thermal decomposition temperature $\left(\mathrm{T}_{\max }\right)$ can be obtained by TG and DTG curves, and thermal denaturation temperature and enthalpy change can be obtained from DSC curves [25]. The results of the thermal properties of hide powder tanned by $\mathrm{CRE}, \mathrm{CNE}$, and CSC are presented in Table 5 and Figs 5-6. As for HCSC, HCRE, and HCNE, the weightlessness rate increased 


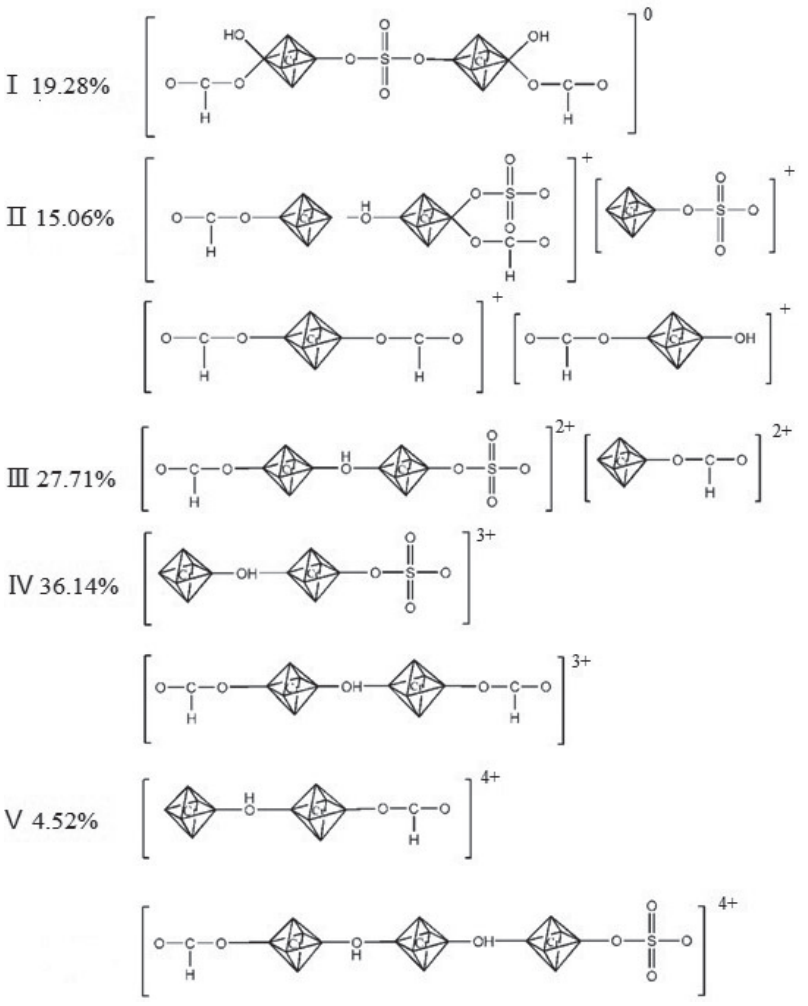

Fig. 3. Structures of CRE.

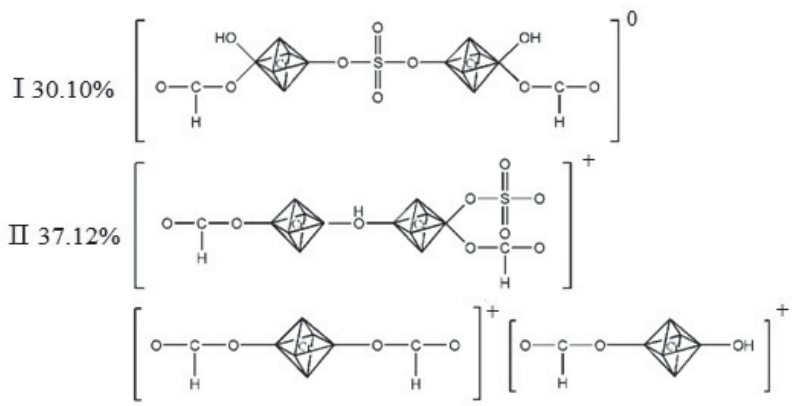

Fig. 4. Structures of CNE.

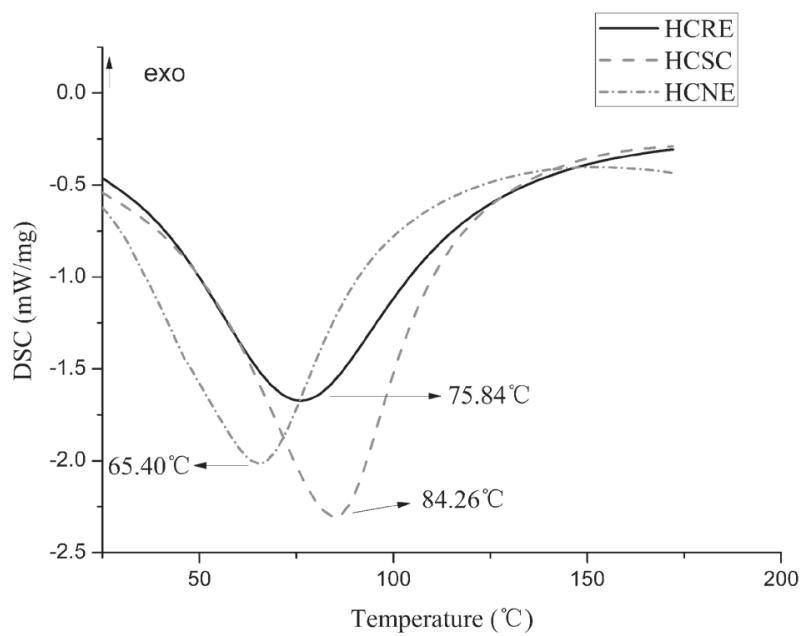

Fig. 5. DSC curves of HCSC, HCRE, and HCNE.

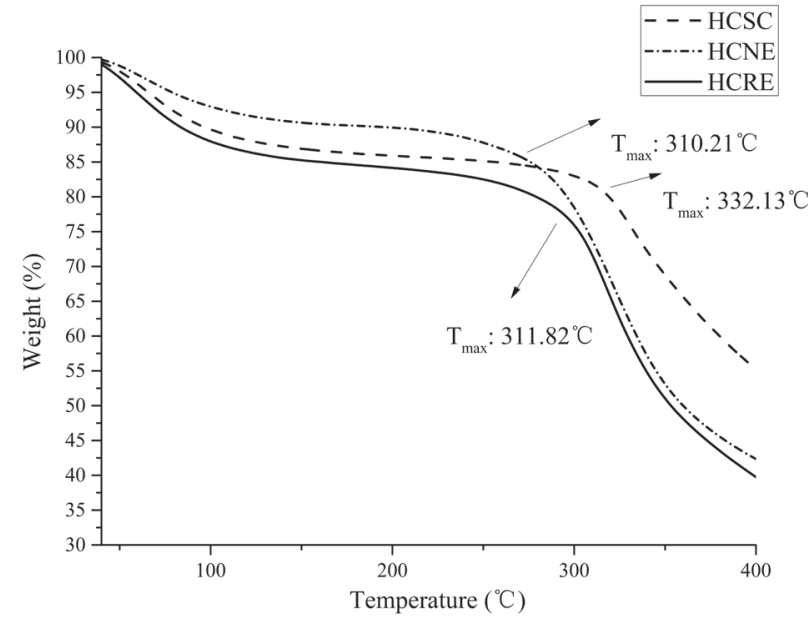

Fig. 6. TG curves of HCSC, HCRE. and HCNE.

Table 5. Thermal properties of hide powder tanned by the chromium recovered from the rewetting and neutralizing effluents.

\begin{tabular}{|c|c|c|c|c|c|}
\hline & $\begin{array}{c}\text { Weightless- } \\
\text { ness rate }(\%)\end{array}$ & $\begin{array}{c}T_{\max } \\
\left({ }^{\circ} \mathrm{C}\right)\end{array}$ & $\begin{array}{c}\text { Thermal } \\
\text { denaturation } \\
\text { temperature } \\
\left({ }^{\circ} \mathrm{C}\right)\end{array}$ & $\Delta \mathrm{T}_{\mathrm{d}}$ & $\begin{array}{c}\Delta H \\
(\mathrm{~J} / \mathrm{g})\end{array}$ \\
\hline HCSC & -30.72 & 332.13 & 84.26 & 0 & 547.85 \\
\hline HCRE & -44.78 & 311.82 & 75.84 & 8.42 & 449.36 \\
\hline HCNE & -48.02 & 310.21 & 65.40 & 18.86 & 346.54 \\
\hline
\end{tabular}

one by one from $30.27 \%$ to $48.02 \%$, and $\mathrm{T}_{\max }$ decreased from $332.12^{\circ} \mathrm{C}$ to $310.21^{\circ} \mathrm{C}$. The thermal denaturation temperature of the tanned powder decreased from $84.26^{\circ} \mathrm{C}$ ( $\mathrm{HCSC}$ ) to $65.40^{\circ} \mathrm{C}$ ( $\mathrm{HCNE}$ ), and enthalpy value dropped from $547.82 \mathrm{~J} / \mathrm{g}$ (HCSC) to $346.54 \mathrm{~J} / \mathrm{g}$ (HCNE; Table 5). According to [26], thermostability decreased with the reduced thermal denaturation temperature and enthalpy change value, so therefore the thermostability of HCRE and HCNE abated in comparison to HCSC. The binding capacity between CRE/CNE and collagen got weak and formed unstable chrome complexes owing to the different structures of CRE, CNE, and CSC, hence the tanning ability of $\mathrm{CRE}$ and $\mathrm{CNE}$ was not good. $(\mathrm{HCSC}=$ hide powder tanned by CSC; HCRE $=$ hide powder tanned by CRE; and $\mathrm{HCNE}=$ hide powder tanned by CNE.)

\section{Conclusions}

Although the rewetting and neutralizing effluents mainly contained anionic-zerovalen and low electropositive chrome complexes, the content of each constituent between them had a lot of differences such as no $+2,+3$, and +4 valent chrome complexes in neutralizing effluents. The molecular weights of chrome complexes in rewetting and neutralizing effluents were smaller than 
those in sulfate chrome liquor of alkalinity $33 \%$ (control). $\mathrm{Cr}^{3+}$ in rewetting and neutralizing effluents primarily combined with $\mathrm{SO}_{4}^{2-}$ and $\mathrm{HCOO}^{-}$through a singlepoint coordination mode. Furthermore, there were fewer bridge linkages between $\mathrm{Cr}^{3+}$ and ligands and the volume was fairly small. Nevertheless, many more single-point coordination modes occurred in neutralizing effluents compared with rewetting ones. The thermal stability of the tanned hide powder decreased far below the control, indicating the weak tanning ability of the released chrome complexes. To summarize, the composition, properties, and structures of chrome complexes in rewetting and neutralizing effluents are understood from the present study. And these characteristics of the complexes have caused a marked change in the tanning properties of the liquors and in the quality of leathers produced. Hence it may include important hints for reducing environmental pollution by improving the tanning process, reducing the release of chromium, and facilitating the development of the effluent recycling technology.

\section{Acknowledgements}

The authors gratefully acknowledge the financial support provided by NSFC (No. 21576171).

\section{References}

1. SUNDAR V.J., MURALIDHARAN C., MANDAL A.B. A novel chrome tanning process for minimization of total dissolved solids and chromium in effluents. J. Cleaner Prod. 59 (15), 239, 2013.

2. GOSWAMI S., MAZUMDER D. Kinetic behaviour of the activated sludge process used for treating composite chrome tannery wastewater. Pol. J. Environ. Stud. 24 (6), 2405, 2015.

3. MWINYIHIJA M. Ecotoxicological Diagnosis in the Tanning Industry. Springer, USA, 21-22, 2010.

4. HACISALIHOGLU S., KARAER F. Relationships of heavy metals in water and surface sediment with different chemical fractions in lake uluabat, Turkey. Pol. J. Environ. Stud. 25 (5), 1937, 2016.

5. IBTAHIM A.A., YOUSSEF M.S.A., NASHY E.S.H.A., EISSA A.M. Using of hyperbranched poly (amidoamine) as pretanning agent for leather. International Journal of Polymer Science. 2013 (5), 1, 2013.

6. MURUGESAN A.G., RAMATHILAGA A., PONSELVAN J.K.S., MICHAEL R.D. Immunotoxicity of tannery effluent to the freshwater fish Cyprinous carpio. Bull. Environ. Contam. Toxicol. 88 (4), 639, 2012.

7. ZHANG C.X., XIA F.M., LONG J.J., PENG B.Y. An integrated technology to minimize the pollution of chromium in wet-end process of leather manufacture. Journal of Cleaner Production. 154, 276, 2017.

8. KUMAR M.P., ARAVINDHAN R., SREERAM K.J., RAO J.R., NAIR B.U. Green chemistry approach in leather processing: a case of chrome tanning. JALCA. 106 (4), 113, 2011.

9. MELLA B., GLANERT A.C., GUTTERRES M. Removal of chromium from tanning wastewater and its reuse. Process Safety and Environmental Protection. 95, 195, 2015.
10. MALEK A., BENOTMANE B., ARIBI C., HACHEMI M. Chemical transformation of chromed leather wastes into environmentally harmless fibrous biomass. Environment Protection Engineering. 42 (3), 179, 2016.

11. ELABBAS S., OUAZZANI N., MANDI L., BERREKHIS F., PERDICAKIS M., PONTVIANNE S., PONS M.N., LAPICQUE F., LECLERC J.P. Treatment of highly concentrated tannery wastewater using electrocoagulation: influence of the quality of aluminium used for the electrode. Journal of Hazardous Materials. 319 (SI), 69, 2016.

12. GOLDER A.K., SAMANTA A.N., RAY S. Removal of chromium and organic pollutants from industrial chro me tanning effluents by electrocoagulation. Chemical Engineering and Technology. 34 (5), 775, 2011.

13. CHENG B.Z., YANG F., ZHANG L., CAO S. The research to remove the chrome from retanning-fatliquoring waste water. Leather Science and Engineering. 24 (6), 39, 2014.

14. ZENGIN G., OZGUNAY H., AYAN E.M., MUTLU M.M. Determination of dyestuffs remaining in dyeing processes of vegetable-tanned leathers and their removal using shavings. Pol. J. Environ. Stud. 21 (2), 499, 2012.

15. CHAI X.W., GAO M.M., WANG Y.N., ZHANG W.H., LIAO X.P., SHI B. Chrome concentration in wastewaters of post-tanning processes and the analysis of its origin. Leather Science and Engineering. 23 (6), 40, 2013.

16. ZHANG J.W., FU M.M., SUN H.B., QIN W.F., GAO Y.P., CHEN W.Y. Release of chromium in post tanning process of chrome tanning without pickling. China Leather. 43 (21), 9, 2014.

17. WANG H., ZHANG C.X., GUAN Y.F., PENG B.Y. Influence of $\mathrm{pH}$ on chromium release in post -tanning processes of wet-blue leather. China Leather. 43 (9), 16, 2014.

18. ZHOU J., HU S.X., WANG Y.N., ZHANG W.H., LIAO X.P., SHI B. Chrome release in chrome-tanned leather during dyeing and fatliquoring processes. China Leather. 42 (9), 21, 2013.

19. LIAO L.L., CHEN W.Y. Beamhouse. In Tanning Chemistry and Technology, 1st ed.; Science Press, China, Volume 1, 186, 2005.

20. ZHANG J.W., GAO Y.P., CHEN W.Y. Characteristics of chrome complexes in neutralizing effluent. Leather and Footwear Journal. 17 (1), 45, 2017.

21. SHANTHI C., BANERJEE P., BABU N.K.C., RAJAKUMAR G.S. Recovery and characterization of protein hydrolysate from chrome shavings by microbial degradation. JALCA. 108 (6), 231, 2013.

22. LIU Z.H., LU L.M., TANG Y.W. Thermal Analysis Brief Tutorial, Science Press, China, 1-243, 2012.

23. TAKENOUCHI K. Composition of complexes in chrome tanning liquors and its effect on heat resistance. Journal of the Faculty of Agriculture Hokkaido University. 60 (3), 194, 1981.

24. CHEN W.Y., LI G.Y. (2011). Tanning Chemistry, 3rd ed.; China Light Industry Press, China, 44-46, 2011.

25. ZHANG J.W., HAN Z.W., TENG B., CHEN W.Y. Biodeterioration process of chromium tanned leather with Penicillium sp. International Biodeterioration and Biodegradation. 116, 104, 2017.

26. BUDRUGEAC P., BADEA E., DELLA GATTA G., MIU L., Comanescu A. A DSC study of deterioration caused by environmental chemical pollutants to parchment, a collagen-based material. Thermochimica Acta. 500 (1-2), 51, 2010. 